\title{
APPLICATION OF OPERATION RESEARCH AND SYSTEM SCIENCE APPROACH TO FISHERIES MANAGEMENT
}

\author{
Lin Sun $^{1}$, Shouju $\mathrm{Li}^{2, *}$, Hongjun Xiao ${ }^{1}$, Dequan Yang ${ }^{1}$ \\ ${ }^{1}$ School of management of Dalian University of Technology, Dalian, P. R. China 116024 \\ ${ }^{2}$ Department of Engineering Mechanics, Dalian University of Technology, Dalian, $P . R$. \\ China 116024 \\ * Corresponding author, Address: Department of Engineering Mechanics, Dalian University \\ of Technology, Dalian, P. R. China 116024,Email:lishouju@dlut.edu.cn
}

Abstract: Marine fisheries are highly complex and stochastic. A simulation model, therefore, is required. Simulation-based optimization utilizes the simulation model in obtaining the objective function values of a particular fishing schedule. The decision support system for fishery management will assist the government agencies and the fishing industry to use sound data and management science techniques in making policy decisions for fishing activities. Transferable rights to fish have proved a reliable and effective means of creating incentives to conserve marine resources. By strengthening individual fishing rights under flexible quota management systems make a significant contribution to conserving fish stocks, to reducing excess capacity and to raising the profitability of the fisheries industry.

Key words: fishery management, optimization approach, decision support system, sustainable fisheries management

\section{INTRODUCTION}

The ocean provides a substantial resource that could yield considerable benefits through fisheries management. The major concern in managing the fisheries issue is to take advantage of this huge resource without damaging the supply in the long run. As a result the government sets certain rules and regulations on fishing vessels in terms of the amount and the species of the

Please use the following format when citing this chapter:

Sun, L., Li, S., Xiao, H. and Yang, D., 2009, in IFIP International Federation for Information Processing, Volume 294, Computer and Computing Technologies in Agriculture II, Volume 2, eds. D. Li, Z. Chunjiang, (Boston: Springer), pp. 1359-1368. 
fish they could catch in any given day and in any given area. Laying out these decisions and implementing them forces the fishery management organization to make some decisions that they may not be sure themselves if they could result desirable solutions. In practice, these decisions force fishery vessels to fish a specified amount of each species at any given time. Such decisions are difficult due to the complexities associated with multiple management objectives and multiple alternatives under considerations. To aid the decision making process, managers need tools to formalize these complexities into a common framework consisting of relationships among management measures, sources of uncertainty, and possible outcomes of actions (Azadivar et al, 2008).

Unregulated fisheries tend to be characterised by overexploitation of the stocks. In relation to this, there has been an extensive search for management measures to reduce fishing effort. A number of neo-classical economists have argued that two measures will reduce fishing effort in an efficient way: taxes and individual transferable quotas (ITQs). Other measures, such as nontransferable individual quotas, a total allowable catch with temporary closure of the fishery, and effort regulations are not Pareto-efficient. Institutional economists have criticised neo-classical theory for neglecting political problems, enforcement problems, and transaction costs. They argue that because of such problems, the superiority of taxes and ITQs for fisheries management is questionable.

Even though the main objective of fisheries management is to move towards sustainable fisheries, most efforts have failed. Management of some fish stocks is facing dysfunctional national and international cooperation, and available resources are decreasing. Academic disciplines such as biology, economics, and social sciences provide valuable information to fisheries management. Still, the solutions they offer only solve parts of the complex problems the management is facing, as most of the solutions are limited to the discipline within which they are proposed. Individual transferable quotas (ITQ) may, for example, be considered as economic efficient by economists, marine protected areas (MPA) as ecosystem-friendly by biologists, and community based management (CBM) as a goal to social anthropologists (Ingrid et al, 2006).

The Decision Support System (DSS) is a computer program that transfers information from research surveys, and commercial fishing reports into advices for policy makers on decisions of when, where and how much fishing effort should be allocated (Truong et al, 2005). The core of the DSS is the component that intensively applies simulation modeling and operations research techniques. The Decision Support System for Fishery Management will assist the government agencies and the fishing industry to use sound data and management science techniques in making policy decisions for fishing activities. 
Technical and social systems increase in their complexity and vulnerability, and human-made systems, such as the fisheries, are not in conformance with natural systems. Industrial ecology is a framework for organizing production and designing consumption systems in ways that resemble natural ecosystems to achieve a more efficient industrialization, adjusted to the tolerances of natural systems (Fet, 1997). Technology should work with natural systems, not against them. In a natural system there is a causal relation between causes and their effects. The natural cause and effect relationships are the designer's advantage when human-made systems are being designed (Asbjornsen, 1998).

\section{SYSTEM SCIENCE APPROACH TO FISHERIES MANAGEMENT}

Management science, the scientific study of problem-solving, has developed a body of literature and methodologies over the past four decades on decision theory methods, evaluation of management and systems performance, and analysis of systems under uncertainty. These methods have been influential and applied successfully to many industrial decision-making and strategic-planning settings. Fisheries management has not yet embraced these innovations, which involve the "scientific method of problem-solving" and which offer considerable opportunity for improved fisheries decisionmaking. Fisheries science and management can be integrated with management science in what we term "fisheries-management science". The broader framework allows management in the face of uncertainty and, at the spatial and temporal scales, is appropriate for the complexity of fisheries systems. This paper presents an implementation plan for fisheriesmanagement science in a commercial fishery. The implementation plan is presented as a possible remedy for issues that have plagued fisheries management to date. It is argued that decision theory methodologies are needed to analyse the management problem context, including strategic planning and objectives setting, appropriate spatial and temporal scale definition, interdisciplinary systems modelling methods, the assessment and management of risk, and ongoing in-season decision-monitoring. The fisheries-management science problem-solving context also provides a basis for reshaping the central agency responsible for fisheries into a more actionorientated organization consisting of multidisciplinary teams acting in support of participative, real-time decision-making through enhanced industry and stakeholders' responsibility for resource sustainability. Fisheries institutions are often hindered by rigid, disciplinary organizational structures and decision-making processes that are unable to account, in a timely fashion, 
for the multiple and conflicting objectives and the inherent variability that characterize a fishery system. The fisheries-management science approach addresses these issues by focusing on the problem-orientated nature of fisheries management, by managing according to objectives, and by supporting a holistic view for stock conservation and resource sustainability.

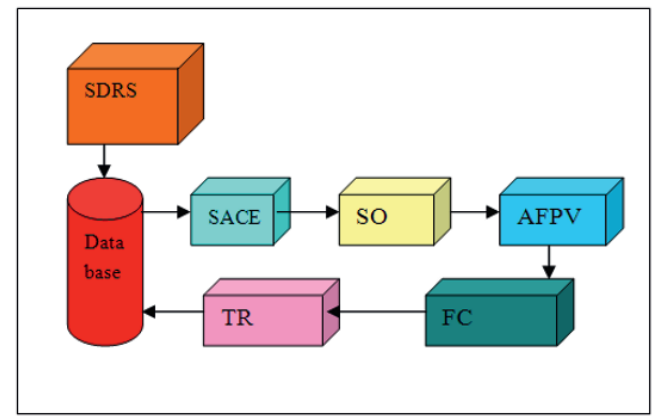

Fig.1: Decision support system for fisheries management

Decision support system for fisheries, as shown in Fig.1, consists of seven components: (1) sampling design and research survey (SDRS), (2)database and data management, (3) statistical analysis on catch or effort(SACE), (4) simulation optimization(SO), (5) allocation of fishing permits to vessels, (6) fishing activities, and (7) trip reports. A systems engineering approach to the fisheries involves connecting and describing objects and events. A life-cycle orientation that addresses the various system phases, i.e., design and development, production, distribution, operation, maintenance, retirement and disposal, is emphasized. If a system is to be analyzed in a holistic manner, it is necessary to consider all system phases, and identify the most important of these. When considering the fisheries, there are several life cycles, e.g., the life cycles of the fleets, of the individual vessels, of the equipment onboard each vessel, and of the fish. The fish is influenced by the fisheries during its entire life cycle, by ecosystem disturbances, and by emissions from production and disposal of technologies. The main interaction between the fish and the fishing fleet is in the fishing fleets' operational phase. It is common to divide systems into four main categories; hardware, software, bioware (or personnel), and economy. The hardware category is related to all physical parts of the system, i.e., parts that can be manufactured by means of technology, such as the fishing vessels. The software category is related to computer programs, instructions or general procedures, laws and regulations, and may be associated with information science and science of law (Ingrid et al, 2006).

The bioware category is related to human elements; human interaction with the system, connected to social science. Publications on Actor-Network Theory in fisheries are examples of research on human interaction within the 
fisheries. The economy category is related to monetary aspects, i.e., financial science. A system may be viewed as a combination of some or all of these categories. The four system categories can be related to the economic, ecological, and social dimensions of sustainable fisheries. Inputs from biologists are important to the fisheries management in order to optimize and design the best management system. The way the systems engineering principles are related to fisheries management in this article, means that fisheries management is the system to be analyzed, not the fish itself and the marine ecosystems. The overexploitation of fish is the primary driver for the need for sustainable fisheries and a well-functioning management system. In this context, fish may be considered as part of the natural system interacting with the human-made system of the fisheries and fisheries management.

\section{OPTIMIZATION PROCEDURE TO FISHERIES MANAGEMENT}

In case of multi-species fishery this problem is even more complex due to the fact that the spatial factors must be explicitly incorporated into the decision making process. There are several important management policy issues that cannot be evaluated without spatial analysis and modeling. Examples of these issues include determination of the location and size of marine protected areas, and judgment on whether the fishing effort displaced to protect the reserves may end up doing more harm elsewhere (Azadivar et al, 2008). The core component of the decision support system is the engine for application of simulation modeling and optimization techniques. The simulation function evaluates the performance of an area management plan based on a set of criteria. The optimization algorithm determines the optimal fishing effort allocation in terms of time, location and amount of catch. For example, fishing efforts in each sub-area and time period are controlled to maximize the value of landings, while bycatch is minimized and other management goals are achieved.

Multispecies fishery is characterized by the geographical overlap of healthy and overfished stocks. The total allowable catch (TAC) for each stock is often calculated using single species models such as maximum sustainable yield or yield per recruit model. By using single species models, technical interactions or bycatch cannot be taken into account. As a result, target catch for all stocks cannot be reached at the same time. In this section, we present a multispecies age-structured model that can be used to calculate the optimal inter-annual management strategy. The optimal inter-annual fishing trajectory is determined by solving the following problem with respect to decision variable 


$$
\begin{aligned}
\text { Max } & J=\sum_{i=1}^{I} V_{i} \\
\text { ST. } & B_{s I} \geq B_{s}^{*}
\end{aligned}
$$

Where $J$ is objective function. $B_{s}^{*}$ is the biomass target for stock $s$ at the end of the planning horizon. $V_{\mathrm{i}}$ is the value of the total landings in year $i$, which can be calculated by

$$
V_{i}=\sum_{s=1}^{s} y_{s i} \times e_{s}
$$

Where $e_{\mathrm{s}}$ is the price per ton of species $s . y_{\mathrm{si}}$ is the annual landing in weight of stock $s$ in year $i$ is calculated as [1]

$$
y_{s i}=\sum_{a=1}^{A} C_{a s i} \times w_{a s}
$$

Where $\mathrm{w}_{\mathrm{as}}$ is the average weight of a species s fish at age $a . C_{\text {asi }}$ is the number of fish in age a cohort of stock $s$ caught during year $i$. This optimization problem is non-linear, and may be stochastic if uncertainty factors in recruitment and catch are taken into account. In order to solve this problem, we use the simulation-based-optimization approach. A Genetic Algorithm is employed as the optimization engine for controlling the optima searching process. The value of the objective function, the total worth of the catch, is estimated for each scenario by simulating the corresponding system.

\section{SUSTAINABLE FISHERIES MANAGEMENT}

The world's fisheries are facing an impending crisis. This crisis will not only affect the natural biological diversity and ecology of the planet's oceans and aquatic ecosystems, but also the social and economic well-being of the individuals and communities dependent on fisheries resources for their livelihoods. With the declines in global fish stocks and the uncertainty in the ability of some stocks to rebound from extremely low population levels, there is now mounting evidence that the world's commercial fisheries may face complete collapse by the middle of the 21 st century. It is imperative now, more than ever, for fisheries to become truly sustainable and for people who exploit fisheries resources to shift towards more sustainable practices in the world's fisheries. What's more, the current crisis facing the world's commercial fisheries seriously brings into question the ability of centralized government agencies to act as the primary managers of these common pool resources. It is becoming ever more apparent that such 'top-down' fisheries management techniques are not effective in achieving either ecological or social sustainability. Despite the best efforts of government agencies to 
manage fisheries through market-driven individual transferable quotas (ITQs) based on scientific models for maximum sustainable yield (MSY) and total allowable catch (TAC), fisheries continue to decline and the fisheries communities that depend on them are slowly decaying. In recognizing the need to decentralize the management of coastal resources, many scholars have advocated for local communities and/ or resource users to play a greater role in managing the fisheries resources on which they depend (Thompson, 2008).

Government-based attempts have often failed to manage marine resources in a sustainable way. Co-management and the recognition of fishers' knowledge is hence increasingly considered a remedy for overfishing in coastal fisheries. Co-management can be defined as the collaborative and participatory process of regulatory decision-making among representatives of user groups, government agencies and research institutions. Despite the recognition of the potential benefits of fisheries co-management and its close linkages to ecosystem-based approaches to fisheries, difficulties are frequently encountered during its implementation (Jentoft et al, 2008). A marine biological study confirms this observation by depicting a reduction in the average sizes and lower reproduction rates. Several fishing grounds are considered either fully exploited or overexploited, which is threatening the local fishers' main source of income and the region's most important economic activity (Pollack et al, 2008).

In recognition of the limitations to traditional conservation awareness campaigns, participants and environmental educators involved in CBCM fisheries should be seeking new techniques to more effectively bring about sustainable fishing activities. Marketing (CBSM) is an emerging tool that has been shown to be extremely effective at fostering sustainable behavior. CBSM combines social psychology and social marketing in a systematic way in order to maximize the success of implementing sustainable development projects. CBSM has been successfully utilized in many resource management sectors such as energy and water conservation initiatives, waste recycling, and reduction programs, and watershed management programs. Despite its successes in these areas of resource conservation and management, CBSM has rarely been used to foster sustainable behaviors related to fisheries conservation and management. In particular, this system has never been applied within the context of CBCM fisheries, despite the fact that CBSM and CBCM fisheries both have a strong focus on community level education and direct participation in nurturing more sustainable behaviors for the conservation of resources. Communitybased co-management (CBCM) is a peoplecentered, community oriented, resources-based partnership approach to fisheries management in which government agencies, the community of local resource users, nongovernment organizations, and other stakeholders share the 
responsibility and authority for the management of a fishery. It aims to devolve power from central agencies, while empowering and building capacity within communities to manage local fisheries resources in a more sustainable manner (Thompson, 2008).

Sustainable management regimes fail if stakeholder participation is merely conceived to create 'a sense of ownership', to enrich available knowledge and to bargain compromises between a-priori conflicting interests. Preferences and attitudes of actors are subject to change during dialogue in a joint effort: Their views on other actors, their understanding of other actors' perspectives and their modes of relating with the natural environment evolve in response to new insights and positive experiences in a deliberative participatory arena. This requires skilled facilitation and an enabling environment for such an arena-often unmet preconditions. But our point here is that non-cognitive aspects play an important role, which cannot be captured by a restrictive understanding of "trustbuilding" in terms of "acceptance of a given structure". The procedural dimension of jointly developing a management structure is maybe as relevant as the regulations that come out of it. The quality of societal interaction, the identification with an area and its appreciation, the experienced plurality of positions, the empowerment of actually influencing a decision, but also the responsibilities coming along with it, and finally the experienced limitations imposed by legislation and the existing power relations - these aspects can develop during a continued and meaningful stakeholder process and are highly relevant for the sustainability of a management regime (Escobar, 1984).

Despite its popular application by local governments and municipalities, utility providers, and some environmental groups, CBSM has rarely been used to deal with fostering sustainable behaviors in common pool resource sectors such as fisheries. Perhaps the most well documented use of CBSM that provides the best rationale for its useful application in fisheries resource management comes from the agricultural sector and watershed protection campaigns. Like fishers, farmers tend to have a fairly high level of community cohesion, and are directly involved in the use of the environment on which they depend for their livelihoods. Thus, farmers are likely to have similar concerns when it comes to managing their resources. Recognizing the importance of water and soil conservation, reducing pollution and pesticides, and preserving local watersheds from excessive agricultural runoff has prompted community-based social marketers to design campaigns to foster sustainable behavior amongst local farmers. For example, Lynne et al. demonstrated the successful use CBSM techniques to get Florida strawberry farmers to adopt state enforced water saving irrigation technologies. Using surveys, the authors were able to identify the barriers to implementing such technologies, and found that farmers needed to feel that they had greater control over adopting water saving devices. As in fisheries management, empowerment has been identified as an important element of 
local fisheries management. Such empowerment and control is more easily secured when resource users are in a position to participate and give input on management decisions to ultimately achieve greater self-control (Jentof, 1984).

The technological development within the fisheries fleet leads to environmental problems, i.e., increased engine size leads to increased emissions of greenhouse gases. It may be more difficult to measure the exact amount of greenhouse gas emissions than increased average breadth of the fishing vessels; at least such figures cannot be calculated without introducing uncertainty. Since reduction of overcapacity in the fisheries fleet is in accordance with management objectives of achieving sustainable fisheries, and since overcapacity is related to technical parameters of fishing vessels, then frequent measurement of performance indicators based on technical parameters, would be a valuable contribution to the achievement of sustainable fisheries (Standal, 2005).

\section{CONCLUSION}

The optimization approach is applied to a harvesting and scheduling problem for a fishing fleet. The comparison between the simulation of status quo and the result of the optimization program shows that the current fishing activities are far from the optimum and the net profit can be improved significantly by adjusting the time, location and targeting species. Implementation of industrial ecology into fisheries management brings system thinking in ecology together with systems engineering and economics. The systems engineering method mainly uses the top-down approach, based on the point of view that the whole is more than just the sum of its parts. One of the most important attributes of systems engineering is the continuous evaluation process. As the system is analyzed, it is also evaluated at the different life-cycle stages in order to improve the system through the whole process. A potential benefit from implementing systems engineering into fisheries management is more transparency and a reduction of the risks associated with the decision-making process. Increased visibility is provided through the perspective on the system from a long-term and lifecycle perspective.

\section{REFERENCES}

A. Escobar. Discourse and power in development: Michel Foucault and the relevance of his work to the Third World. Alternatives, 1984; 10: 377-400 
A. M. Fet. Systems engineering methods and environmental life-cycle performance within ship industry. PhD thesis, Norwegian University of Science and Technology, Trondheim, Norway; 1997.

B. U. Ingrid. Systems engineering principles in fisheries management, Marine Policy, 2006, 30: 624-634

D. Standal. Nuts and bolts in fisheries management - a technological approach to sustainable fisheries? Marine Policy 2005, 29: 255-63

F. Azadivar, T. Truong, Y. Jiao. A decision support system for fisheries management using operations research and systems science approach, Expert Systems with Applications 2008, doi:10.1016/j.eswa.2008.01.080

G. Pollack, A. Berghofer, U. Berghofer, Fishing for social realities-Challenges to sustainable fisheries management in the Cape Horn Biosphere Reserve, Marine Policy 2008,32: 233-242

H. Myles, Thompson. Fostering sustainable behaviours in community-based co-managed fisheries, Marine Policy 2008,32: 413-420

N.A. Carrick, B. Ostendorf. Development of a spatial Decision Support System (DSS) for the Spencer Gulf penaeid prawn fishery, South Australia, Environmental Modelling \& Software 2007,22: 137-148

O. A. Asbjornsen. Systems engineering and industrial ecology. Maryland, USA: Skarpodd; 1998

S. Jentoft. Fisheries co-management as empowerment. Marine Policy, 2005, 29:1-7

S. Jentoft, B. J. McCay, D. C. Wilson. Social theory and fisheries comanagement. Marine Policy 1998; 22(4-5):423-36

T. H. Truong, J. B. Rothschild, Decision support system for fisheries management, Proceedings of the 2005 Winter Simulation Conference, 2005, 2107-2111 